\title{
Lírica dos Trovadores Medievais
}

\section{Gérard Gonfroy}

No alvorecer do século XII, em torno do ano 1100 , nasceu ao sul da França, no país $d^{\prime} o c$, um movimento poético cuja influência direta se expandiria por toda a Europa durante os dois séculos seguintes e cuja ressonância longínqua não cessa de ditar os comportamentos amorosos, ao menos os do Ocidente: refirome à lírica trovadoresca, mais conhecida pela ideologia cortês que contribui a instaurar do que por suas 2600 peças cuja virtuosidade formal, densidade poética e língua utilizada, - o occitan - tornam o acesso difícil ${ }^{1}$ ao "honnête homme" de nossa época.

Com Guilherme IX de Poitous (1071-1126), primeiro trovador conhecido, assiste-se a uma dupla ruptura: primeiramente uma ruptura lingüística, pelo emprego da língua vulgar, o occitan, enquanto as formas literárias em uso (com objetivos edificantes) exprimiam-se unicamente em latim, e, em seguida, uma ruptura cultural, pela aparição de uma poesia lírica de inspiração profana, inteiramente consagrada ao amor do qual não ignorará as mais cruas realidades. Com ele e seus sucessores imediatos estabelece-se uma nova concepção das relações entre homens e mulheres, fundada sobre uma inversão completa dos valores: em uma sociedade onde contavam unicamente as relações de força, eis que o trobador (aquele que troba, isto é, "aquele que inventa texto e melodia"), qualquer que seja sua categoria, renuncia aos privilégios de seu sexo e de seu estatuto para fazer-se vassalo por amor. Tal é a revolução imposta pela fin'amors ("amor purificado/depurado") e atualizada pela incansavelmente repetida metáfora vassálica: a domna (dama) é a suzerana, enquanto o homem é seu vassalo, seu servidor (servire); e o serviço feudal transforma-se em serviço amoroso, cujas práticas, direitos e deveres recíprocos são codificados com 0 mesmo rigor que na sociedade englobante. De onde as queixas incessantes do irobador, que critica o rigor de sua dama, sua deslealdade ou sua falta de generosidade. Evidentemente, convém distinguir cuidadosamente o universo ficcional assim criado e as realia, completamente diferentes, que, durante séculos

Eêrard Gonfroy é Professor da Universidade de Limoges (Professor convidado pela Universidade Federal do Rio Grande do Sul em 1993 - acordo CAPES/COFECUB).

fradução: Zilá Bernd (Professora na Universidade Federal do Rio Grande do Sul).

Sem falar da dispersão do corpus em centenas de edições diferentes das quais muitas estão atualmente egotadas. E por isso que o TELMOO (Texte Lyrique Médieval d'Oc et d'Oil), grupo de pesquisas da Uiversidade de Limoges, empreendeu, sob minha direção, a reunião da integralidade da obra dos îvadores. Esta "Integra dos trovadores" será publicada sob a égide da Associação Internacional de Fitudos Occitans em 1994; ela apresentará a forma eletrônica de um CD-ROM, o que permitirá interrogar it eonjunto como se se tratasse de um único texto. O conhecimento da língua, do imaginário e das iepresentações mentais dos trovadores ficará assim extremamente facilitado. 
ainda, concederão à mulher apenas um lugar subalterno. Isto não impediu que o Imaginário amoroso do Ocidente fosse marcado para sempre por esta influência.

O amor cortês dos trovadores, a fin'amors, repousa igualmente sobre um conjunto fechado de valores, atualizados por lexemas-chave cuja presença no interior do texto vem preencher a expectativa dos receptores. No coração desta rede, joi designa precisamente a exaltação que toma conta do amante-poeta ao ver, ao pensar, ou ao lembrar-se de sua dama. O termo francês "joie" (alegria), conotado de passividade, traduz mal a pulsão conquistadora, a tonicidade cósmica que o trovador interioriza a partir de elementos exteriores, como a renovação da primavera, tão propícia à emoção amorosa (ver, por exemplo, a estrofe de abertura das peças 1 e 3 ). Ligado ao precedente, joven ("jeunesse"/juventude) evoca as qualidades de disponibilidade e de espontaneidade, atribuídas à juventude do coraçâo e indispensáveis à concretização da fin'amors; igualmente, a necessária mesura acentua as qualidades de paciência, discrição, moderação e respeito, enquanto que a cortezia ("courtoisie"/cortezia) representa a face socializada, ditando a atitude pública do amante perfeito. Finalmente, a largueza ("générosité"/generosidade) aplica-se ora à liberalidade do senhor, isto é, do marido da domna, ora à sua ausência de ciúme, ora, sob sua face feminina, a mercés ("merci"/agradecimento), às recompensas distribuídas pela dama.

Poesia aristocratizante, senão aristocrática, a lírica dos trovadores enearna-se em uma forma privilegiada do grande canto cortês, a canso ou canção de amor. Caracterizada pela divisão em estrofes ou coblas, ${ }^{2}$ a canso remete a uma ìituaçڤ̆o enunciativa sempre idêntica: o $e u$ do amante-poeta dirige, fora de toda a iemporalidade, uma queixa lírica a uma domna, projetada em uma transcendência de principio e existencialmente ausente. Entre os dois actantes principais insinuam-se personagens alusivos, jamais individualizados, os lauzengiers ("médisants"/intrigantes) cuja função essencial consiste em denunciar os amantes eulpados junto ao senhor e em denegrir o trovador diante de sua dama. Em suma: ivais no amor e concorrentes na poesia. Mais profundamente, os lauzengiers imbolizam os obstáculos dos quais se nutre a fin'amors: o afastamento Heográfico, a inacessibilidade social (ela é de alta extração social) e moral da dima (cla é casada); todos esses fatores reforçam e valorizam a transcendência da domma. Espera-se, então, que a fin'amors funcione como uma verdadeira escola de aperfeiçoamento cultural e moral para permitir ao trovador alçar-se ao nível da dima. Seria, contudo, um grave contrasenso confundir erótica trovadoresca e amor platônico. A idealização da mulher nunca se opera em detrimento dos prazeres carnais. Esta situação-tipo, já presente na obra dos primeiros trovadores, eonhece seu apogeu na idade clássica (1150-1180), representada perfeitamente por nosso exemplo 2, de Bernart de Ventadorn, antes de ter sido desvirtuada, a seguir, como a leitura da peça seguinte de Arnaut Daniel permite perceber.

1 Com efeito a cobla é o princípio unitário do poema, quer se trate da melodia, idêntica para todas as eitrofen, ou da estrutura métrica, que se aplica também a cada estrofe.
Poderíamos temer que esta estereotipia do texto trovadoresco engendrasse monotonia e repetição; efetivamente, ela fica minimizada se aceitarmos julgar esta poesia, desfazendo-nos da concepção romântica do lirismo: de fato, nada é mais estrangeiro ao trobar do que a efusão sincera dos sentimentos ou a procura sistemática da originalidade. Marcado pela fixação fundamental das situações e dos temas, o trobar afasta-se disto pela infinita diversidade de formas e de motivos secundários, quer se trate de luxuriantes estruturas formais (mais de 1000 estruturas formais diferentes em 2600 peças!) ou da habilidade com a qual os motivos mais freqüentes, tal como o exórdio primaveril, encontram-se sutilmente desconstruídos/reconstruídos de poema para poema.

Esta arte de artesão, no sentido nobre do termo, nascida ao sul de Poitou e no Limousin, onde difundiu-se de corte em corte antes de conhecer uma rápida expansão em território occitan, primeiro na Auvergne e no Languedoc, depois na Provence e na Catalunha, fascinou imediatamente a Europa inteira. Desde os primeiros anos do século XII, o trobar expandiu-se efetivamente fora de suas fronteiras lingüísticas, atingindo a França do norte (trouvères), a Galícia e Portugal (poesia galaico-portuguesa) e mesmo a Alemanha (Minnesanger), fornecendo, assim, esquemas estruturais e motivos a líricas que se afastarão, com maior ou menor felicidade, da predominância dos modelos occitans.

O leitor moderno deixa-se fascinar pela complexidade das estruturas formais, pelo domínio do significante poético e pela habilidade retórica de que fizeram prova os melhores trovadores; ele reconhece bem, para além de uma riqueza combinatória quase sem limites, a marca distintiva dos grandes criadores, aqueles cuja busca obstinada do verbo poético funda a escritura. Deixa-se sobretudo seduzir pelo jogo do desejo contrariado que funda a erótica trovadoresca, animada por uma perpétua tensão em direção a uma saciedade que se furta incessantemente...

\section{EXPLICAÇÃO SOBRE A ESCOLHA DAS PEÇAS}

1. Guilherme IX (Ab la Dolchor del Temps Novel) (PC 183,1; por volta de 1100) Os versos do Coms de Peiteus, os mais antigos jamais escritos em uma língua moderna, abrem a aurora do trovar. Esta peça de estrutura simples (5 coblas de 6 octossílabas sobre o esquema 8aabcbc) encanta pelo frescor do tom (v.12-18), pela elegância das alusões à conquista amorosa (v. 20), pela mercès da dama (v.21-22) e por seu erotismo sorridente (v.23-24,36).

\section{Bernart de Ventadorn (Lo Tems Vai e Ven e Vire) (PC 70,30; por volta de} 1150)

Bernart, cuja obra é inteiramente dedicada ao amor, é considerado justamente, como o modelo do trobar leu (estilo leve) e como o mestre da erótica clássica. A peça escolhida oferece um bom florilégio dos principais temas de Ventadorn (a persistência do desejo no seio de um universo em constante 
mutaçẩo, o rigor da dama, a paradoxal renúncia ao canto, a fragilidade da felieidade, a beleza física e moral da domna, etc.)

I. Armaut Daniel (Chanzo Don L' Mot Son Plan e Prim) (PC 29,6: por volta de 1200)

Ao contrário, Arnaut Daniel, a quem Aragon consagrou sua Leçon de Riberac, é o mais notável representante do trobar ric (estilo complexo, voluntariamente obscuro e difícil). A peça escolhida mistura os estereótipos da fln'amors (início primaveril, ódio aos lauzengiers) a uma verdadeira arte poética. A situçగ̃o-tipo da canso é aqui desviada por uma distanciação ao mesmo tempo preciosa e irônica. Observar-se-á o domínio do verbo e do ritmo, verdadeiramente excepeional neste trovador, e a complexidade da versificação: seis coblas doblas de 9 versos, seguidas de uma tornada de quatro versos, sobre o esquema: Iaa $4 a b b 6 c^{\prime} 4 \mathrm{dd} 6 \mathrm{c}$ ', as rimas em uelha formando um elemento de estabilidade, enquanto que as três primeiras coblas são capfinidas (a rima interna em uelh é uma rima derivativa em relação à última palavra da cobla precedente).

\section{PECAS DOS TROVADORES EM OCCITAN}

\section{Guilhem de Peiteus ou la naissance du trobar ${ }^{3}$}

Ab la dolchor del temps novel foillo li bosc, e li aucel

chanton, chascus en lor lati, segon lo vers del novel chan:

5 adoncs esta ben c'om s'aisi d'acho dont hom a plus talan.

$$
\text { II }
$$

De lai don plus m'es bon e bel non vei mesager ni sagel,

per que mos cors non dorm ni ri

10 ni no m'aus traire adenan,

tro qu'eu sacha ben de la fi, s'el'es aissi com eu deman.

\section{III}

La nostr'amor va enaissi com la brancha de l'albespi,

15 qu'esta sobre l'arbr'en creman, la nuoit, ab la ploi'ez al gel, tro l'endeman, que 1 sols s'espan per la fueilla vert el ramel.

\section{IV}

Enquer me menbra d'un mati

20 que nos fezem de guerra fi e que $m$ donet un don tan gran: sa drudari'e son anel.

Enquer me lais Dieus viure tan qu'aia mas mans soz son mantel!

\section{V}

25 Qu'eu non ai soing d'estraing lati que m parta de mon Bon Vezi; qu'eu sai de paraulas com van, ab un breu sermon que s'espel: que tal se van d'amor gaban,

30 nos n'avem la pessa e 1 coutel

\section{Bernart de Ventadorn ou la perfection du trobar}

\section{I}

Lo tems vai e ven e vire per jorns, per mes e per ans, et eu, las! no n sai que dire, c'ades es us mos talans.

5 ades es us e no s muda, c'una $n$ volh e $n$ ai volguda, don anc non aic jauzimen.

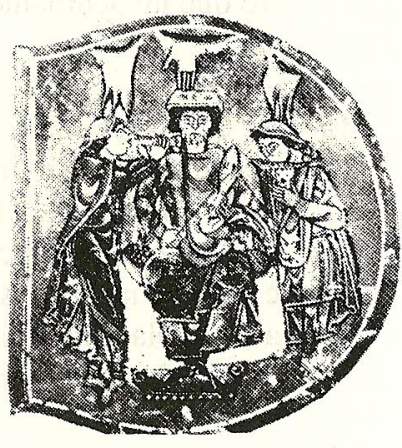


Pois ela no $n$ pert lo rire, a me $n$ ven e dols e dans,

10 c'a tal joc m'a faih assire don ai lo peyor dos tans (c'aitals amors es perduda qu'es d'una part mantenguda) tro que fai acordamen.

\section{III}

15 Be deuri'esser blasmaire de me mezeis a razo, c'anc no nasquet cel de maire que tan servis en perdo e s'ela no m'en chastia

20 ades doblara lh folia,

que: "fols no tem, tro que pren".

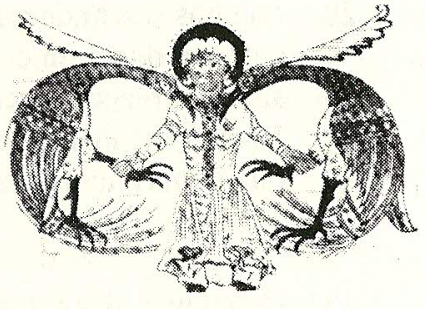

IV

Ja mais no serai chantaire ni de l'escola n'Eblo,

que mos chantars no val gaire

25 ni mas voutas ni mei so;

ni res qu'eu fassa ni dia,

no conosc que pros me sia,

ni no i vei melhuramen.

$$
\text { V }
$$

Si tot fatz de joi parvensa,

30 mout ai dins lo cor irat

qui vid anc mais penedensa

faire denan lo pechat?

on plus la prec, plus m'es dura;

mas si'n breu tems no s melhura,

35 vengut er al partimen.
VI

Pero ben es qu'ela $m$ vensa a tota sa volontat,

40 que, s'el'a tort o bistensa, ades n'aura pietat; que so mostra l'Escriptura: causa de bon'aventura

val us sols jorns mais de cen.

VII

Ja no m partrai a ma vida,

tan com sia sals ni sas,

45 que pois l'arma n'es issida, balaya lonc tems lo gras; e si tot no s'es cochada, ja per me no n er blasmada, sol d'eus adenan s'emen.

\section{VIII}

$50 \mathrm{Ai}$, bon'amors encobida, cors be faihz, delgratz e plas, frescha chara colorida, cui Deus formet ab sas mas! totz tems vos ai dezirada,

55 que res autra no m'agrada. autr'amor no volh nien!

IX

Dousa res ben ensenhada,

Cel que us a tan gen formada, me $\mathbf{n}$ do cel joi qu'eu n'aten! 


\section{Arnaut Daniel ou la distanciation du trobar}

I

Chanzo don 1 mot son plan e prim

far eu ai mas brotonon 1 vim

e 1 auzor sim

so de color

5 de manta flor

e verdeian la fueilla,

e 1 chant e 1 brail

son a l'onbrail

dels aucels per la brueilla.

10 Per ls broilz aug lo chant e 1 refrim e per que hom no $\mathrm{m}$ faza crim

obri e lim

mos de valor

$\mathrm{ab}$ art d'Amor

15 don non ai cor que $m$ tueilla

anz, si be $m$ fail

la sec a trail

on plus vas mi s'orgueilla.

Petit val orgoil d'amador

20 c'ades trebucha so seignor

del luoc auzor

bas el terrail

per tal trebail

que de Joi lo despueilla:

25 dreis es lacrim,

arga e rim

qui contr'Amor janglueilla.
IV

Bella domna vas cui aor

30 ges per jangloil no vair'ailor,

mas per paor

del devinail,

don Jois tressail,

fas semblon que no s vueilla:

35 c'anc no ns jausim

de lor noirim,

mal m'es que lor o cueilla.

Si tot vaus perdos aesdail, mon pensamen lai vos assail

qu'eu chant e vail

40 per 1 joi que $\mathrm{nz}$ fim

lai on partim,

don sovent l'oil mi mueilla:

d'ir'e de plor

e de douzor

45 pro ai que eu m dueilla.

VI

Er ai fam d'Amor don badail

e no sec mesura ni tail:

sols m'o egail

que anc n'ovim

50 del temps Caim

amador menz acueilla

cor trizador

ni baudador,

per que mos jois capdueilla.

\section{VII}

55 Bella, qui que s destueilla,

Arnaus dreit cor

lai o us honor,

car vostre prez capdueilla. 


\section{Guillaume IX de Poitiers ou la naissanee du trobar}

Dans la douceur du renouveau printanier

se feuillent les bois et chantent les oiseaux,

chacun en leur langage,

sur l'air d'un chant nouveau:

il est naturel que chacun se procure

ce qu'il désire le plus.

II

De là-bas où réside toute joie,

je ne vois venir ni messager ni message,

et mon coeur en a perdu le sommeil et le sourire;

je n'ose faire un geste,

tant que je ne sais pas si le dénouement

sera conforme à mes aspirations.

\section{III}

Il en va de notre amour

comme de la branche d'aubépine qui,

la nuit, tremble sur l'arbre,

soumise à la pluie et au gel,

jusqu'à ce que, le lendemain, le soleil se diffuse, par le vert feuillage, sur le rameau.

\section{IV}

Il me souvient encore de ce matin

où nous mîmes un terme à nos querelles

et où elle me fit le don suprême:

son amour et son anneau.

Que Dieu me laisse encore vivre assez

pour que j'aie un jour mes mains sous son manteau!
V

Je n'ai nul souci de ces propos étrangers

qui chercheraient à me séparer de mon Beau Voisin;

je sais ce qu'il en est des paroles,

grâce à un bref proverbe qui dit:

d'aucuns peuvent bien se vanter de leurs amours,

nous, nous en avons la pleine jouissance.

2. Bernard de Ventadour ou la perfection du trobar I

Le temps va et vient et revient

au fil des jours, des mois et des ans,

mais moi, hélas! je ne sais que dire,

car toujours le même est mon désir;

il est toujours le même et ne varie pas:

je désire et j'ai désiré une dame

dont jamais je n'eus la moindre jouissance.

Puisqu'elle n'en perd nullement le rire,

a moi d'en subir peine et dommage,

car elle m'a invité à un jeu

où je suis deux fois battu

(car il est perdu l'amour

qui n'est soutenu que d'un seul côté)

jusqu'à ce qu'elle condescende à un accord.

III

Je devrais bien me blâmer

moi-même, à juste titre

car jamais homme né de mère

ne servit autant en vain;

et si elle ne m'en corrige,

ma folie ne cessera de redoubler,

car "le fou n'a peur que lorsque tombent les coups". 
Plus jamais je ne serai troubadour,

plus jamais je n'appartiendrai à l'école d'Eble

car mon chant ne me sert à rien,

ni mes refrains, ni mes mélodies;

il n'est rien que je puisse faire ou dire,

je le sais, qui me soit bénéfique,

et je n'y vois nulle amélioration.

$$
\mathrm{V}
$$

Bien que je fasse mine d'être heureux

j'ai le coeur désespéré;

Vit-on jamais faire pénitence

avant de commettre le péché?

Plus je l'implore et plus elle m'est cruelle;

mais si bien vite elle ne s'amende,

j'en serai réduit à la quitter.

VI

Pourtant il est bien qu'elle me soumette entièrement à sa volonte,

car, même si elle est injuste ou se dérobe,

elle finira par avoir pitié de moi;

comme le prouve l'Ecriture,

en matière de bonheur

mieux vaut un seul jour que cent.

\section{VII}

Jamais de ma vie, tant que j'en aurai la force,

je ne la quitterai,

car, après que le grain s'en est sépare,

l'épi reste longtemps le jouet du vent; ${ }^{7}$

et bien qu'elle n'ait guère manifesté d'empressement,

ce n'est pas moi qui le lui reprocherai,

pourvu que, d'elle-même, dorénavant, elle se corrige.

I A belle image des vers 45-46 n'est compréhensible que si l'on se rappelle que, dans la conception de Térotique médiévale, l'amour implique la fusion des coeurs. Aussi, une fois la dame (symbolisée ici par l'arma, e'est-à-dire "l'àme" de l'épi de blé, soit le grain) partie, le corps de l'amant, qui a perdu le meilleur de lui-même, qui a perdu son propre coeur, ravi par la dame, reste sans force, exposé au vent, comme l'est lépi de blé (lo gras), quand le grain en a été ôté.

Ah! amour parfait tant convoité

corps bien fait, svelte et ferme!

Ah! tendre visage au teint éclatant,

que Dieu a créé de ses mains!

Depuis toujours je vous ai désirée

et aucune autre ne me plaît,

Je ne veux pas d'un autre amour!

IX

Douce créature à l'éducation parfaite,

que celui qui vous a si admirablement créée

veuille m'accorder cette joie que j'attends de vous!

3. Arnaud Daniel ou la distanciation du trobar

Une chanson dont les mots sont subtils et légers

je dois faire, maintenant que les osiers se couvrent de boutons

et que les plus hautes cimes

sont de la couleur

de maintes fleurs

et que le feuillage verdoie

et que les chants et les cris des oiseaux

retentissent sous l'ombrage

dans les bois.

II

Par les bois j'entends les chants et les refrains,

et pour qu'on ne m'en fasse pas reproche

je travaille et je lime

des mots recherchés

avec l'art d'Amour

auquel je n'ai pas envie de me soustraire;

au contraire, bien qu'il me fasse défaut,

je le suis à la traîne

alors même qu'il devient plus orgueilleux à mon égard. 
Il a peu de valeur l'orgueil de l'amant car toujours il abat son seigneur

du lieu le plus haut

jusqu'au sol

avec tant de souffrances

qu'il le dépouille de la Joie:

il est donc juste qu'il pleure,

se brûle et se consume

celui qui se plaint contre Amour.

IV

Belle Dame que j'adore,

ce n'est pas pour me plaindre que je dirige ailleurs mes pensées,

mais par peur des indiscrets

qui font trembler la joie,

je fais semblant de ne plus vous désirer,

car jamais nous ne nous sommes repus

de la nourriture [des médisants],

il me déplaît de la leur récolter.

Bien que j'erre çà et là sans but ma pensée là-bas vous assaille car je chante et je vaux par la joie que nous ressentîmes à l'heure de nous séparer:

c'est pourquoi souvent mes yeux s'embuent de chagrin et de larmes,

mais aussi de douceur.

car ma douleur me réconforte.

\section{VI}

A présent j'ai faim d'un amour auquel j'aspire,

et je n'observe ni mesure ni règle;

seul me récompense

le fait que jamais on n'entendit parler

depuis le temps de Caïn

d'un amant, qui, moins [que moi]

accueille un coeur trompeur

et mensonger,

c'est pourquoi ma joie est à son comble.
Belle, qui qui cherche à me séparer de vous,

Arnaut court droit

là-bas où il puisse vous honorer,

car votre mérite atteint son comble.

\section{PEÇAS DOS TROVADORES EM PORTUGUES 8}

1. Guillaume IX de Poitiers ou o Nascimento do Trobar I

Na doçura da renovação primaveri

cobrem-se de folhas os bosques e entoam os pássaros o seu cantar cada qual em sua linguagem,

com a melodia de um novo canto:

é natural que cada um procure

aquilo que mais deseja.

De lá onde reside toda alegria,

não vejo chegar nem mensagem nem mensageiro,

meu coração perdeu o sono e o sorriso;

não ouso fazer nenhum gesto,

enquanto não souber se o desenlace

será conforme a minhas aspirações.

III

Assim vai nosso amor

como o galho do espinheiro que,

à noite, tremula sobre a árvore,

exposto à chuva e à geada,

até que, ao amanhecer, o sol resplandeça,

entre a verde folhagem do ramo.

\footnotetext{
${ }^{8}$ Tradução de Zilá Bernd a partir da versão em francês moderno estabelecida por G. Gonfroy.
} 
Lembra-me ainda esta manhã

quando pusemos fim a nossas disputas quando ela ofertou-me o dom supremo:

seu amor e seu anel.

Deixe-me Deus viver tanto ainda

que possa um dia minhas mãos sob seu manto colocar!$$
\mathrm{V}
$$

Não me preocupa a linguagem estrangeira que buscava separar-me de meu Bom Vizinho;

pois das palavras conheço o percurso,

graças a um breve provérbio que diz:

alguns podem vangloriar-se de seus amores,

nós, o gozamos em sua plenitude.

\section{Bernard de Ventadour ou a Perfeição do Trovar}

O tempo vai e vem e volverá

ao longo dos dias, dos meses e dos anos,

mas eu, ai! não sei o que dizer.

pois é sempre igual o meu desejo;

é sempre o mesmo e não muda:

descjo e continuo a desejar uma dama

cujo amor nunca cheguei a fruir

Se ela continua a sorrir,

cabe a mim aceitar a dor c a pena,

pois ela convidou-me para um jogo

onde serei duas vezes perdedor

(pois está perdido o amor

que existe de um só lado)

até que ela admita um acordo.
Deveria eu acusar

a mim mesmo, com justa razão,

pois nunca homem nascido de mãe

serviu-a tanto em vão,

e se ela não me corrigir,

minha loucura não cessará de aumentar

pois "o louco só teme ao sentir os golpes".

IV

Não mais serei trovador,

nunca mais pertencerei à Escola de Ebles,

pois meu canto de nada serve,

nem meus refrões, nem minhas melodias;

nada há que cu possa fazer ou dizer,

bem o sei, que me seja benéfico,

e não vejo nenhuma melhora.

V

Embora finja ser feliz,

Tenho desesperado o coração;

Já se viu fazer penitência

antes de cometer o pecado?

Quanto mais imploro, mais ela é cruel:

mas se $\mathrm{cm}$ breve ela não se emendar

serei obrigado a deixá-la.

\section{VI}

Contudo é bom que ela me submeta

inteiramente à sua vontade,

pois, mesmo que ela seja injusta ou a mim se furte,

acabará por ter piedade de mim;

como o comprova a Escritura,

$\mathrm{cm}$ matéria de felicidade

mais vale um só dia que cem. 
VII

Nunca em minha vida, enquanto tiver forças eu a deixarei

pois, mesmo depois que o grão cai

a espiga permanece longo tempo exposta ao vento; 9

e embora ela não tenha se apressurado,

não serei eu quem a recriminará,

desde que ela se corrija doravante por si mesma.

\section{VIII}

Ah! Amor perfeito tão desejado,

corpo bem feito, esbelto e firme!

$\mathrm{Ah}$ ! terno rosto de tons resplandescentes,

que Deus criou com suas mãos!

Sempre a desejei

e nenhuma outra me agrada,

Não quero outro amor!

\section{IX}

Doce criatura de perfeita educação,

que aquele que tão admiravelmente a criou

queira me conceder esta alegria que eu tanto espero!

\section{Arnaud Daniel ou a Distanciação do Trobar}

Uma canção cujas palavras são leves e sutis

faço-a agora quando os vimes se cobrem de brotos

e quando os mais altos cumes

estão da cor

de variadas flores

e quando a folhagem reverdesce

e quando os cantos e os gritos dos pássaros

ressoam sob a sombra

dos bosques.

Pelos bosques, ouço os cantos e os refrões;

e para que a mim não critiquem

trabalho, cinzelando

palavras rebuscadas

com a arte do Amor

ao qual não desejo furtar-me;

ao contrário, ainda que me faça falta,

eu sigo seu rastro

mesmo quando ele se torna mais orgulhoso a meu respeito.

\section{III}

O orgulho do amante tem pouco valor

pois sempre abate seu senhor

do lugar mais alto

até o solo

com tantos sofrimentos

que o despoja da Alegria:

é portanto justo que chore,

se queime e se consuma,

aquele que do Amor se queixa.

Bela dama que eu adoro,

não é para queixar-me que para longe dirijo meus pensamentos, mas de medo dos indiscretos

que fazem tremer a alegria,

finjo não mais desejar-vos,

pois nunca nos saciamos

com o alimento (dos intrigantes)

desgosta-me deles recolhê-lo.

\section{$\mathrm{V}$}

Ainda que eu erre daqui para lá sem destino

meu pensamento vos assalta

pois eu canto e valho

pela alegria que sentimos

na hora da separação:

é por isso que muitas vezes meus olhos se umedecem

de tristeza e de lágrimas,

mas também de doçura,

pois minha dor me reconforta.

9 A bela imagem dos versos $45-46$ só é compreensivel se lembrarmos que, na concep̧ão da erótica medieval, o amor implica a fusão dos corações. Também, uma vez que a dama (simbolizada por arma, isto 6, a alma da espiga de trigo, ou seja, o grão) tenha partido, o corpo do amante, que perdeu o melhor de si prêprio, "que perdeu seu próprio coração arrebatado pela dama", permanece sem forças, exposto ao vento,
como a espiga de trigo (lo gras), quando o grão é retirado. 
Agora tenho fome de um amor ao qual aspiro, e não respeito nem medida nem regra; somente me recompensa o fato de que jamais ouviu-se falar desde o tempo de Caim de um amante que, menos (do que eu) acolha um coração enganador e mentiroso, por isso minha alegria está em seu ápice.

VII

Bela, quem procurar separar-me de vós, Arnaut correrá para onde puder honrar-vos, pois vosso mérito atinge seu ápice. 